\title{
Manganite Synthesis By Different Methods
}

\author{
MUKHAMETKALI MUSAGALIEVICH MATAEV ${ }^{1}$, SIDDHARTH (MONTU) SAXENA², \\ GENNADY SEMENOVICH PATRIN ${ }^{3}$, ZHANAR YLIASOVNA TURSINOVA ${ }^{1 *}$, \\ ASSEL TAUPYKOVNA KEZDIKBAYEVA ${ }^{4}$, MARZHAN ABDYZHAPAROVNA \\ NURBEKOVA ${ }^{1}$ and GAUKHAR UMIRALIEVNA BAITASHEVA ${ }^{1}$
}

\author{
${ }^{1}$ Kazakh state women's teacher training university, 050000, Aiteke bi, 99, Almaty, Kazakhstan. \\ 2University of Cambridge, Madinley Road, Cambridge, CB3 OHE, United Kingdom. \\ ${ }^{3}$ Siberian Federal University, Svobodny pr. 79, Krasnoyarsk, Russia. \\ ${ }^{4}$ The Karaganda State University of the name of academician E.A.Buketov, \\ Universitetskaya 28, Karaganda, Kazakhstan. \\ ${ }^{*}$ Corresponding author E-mail: zhanar.tursin@ mail.ru
}

http://dx.doi.org/10.13005/ojc/340315

(Received: January 30, 2018; Accepted: February 28, 2018)

\begin{abstract}
Nanostructural dysprosium manganite doped with bismuth, synthesized by three methods: solid-phase, sol-gel and citrate-nitrate. The composition of the synthesized powders was compared to determine the optimal technique. Using $X$-ray diffraction, the influence of annealing conditions on the structure of manganite was studied. The result of XRD showed that manganite, synthesized variants of methods has orthorhombic structure.
\end{abstract}

Keywords: Dysprosium orthomanganite, Sol-gel combustion, Citrate-nitrate combustion, structure, X-ray.

\section{INTRODUCTION}

Preparation of materials in the form of various sediments ${ }^{1-3}$ is referred to the family of the wet synthesis procedures known from a number of advantages compared with traditional high temperature solid state processing methods, such as excellent control of stoichiometry of the final powders with the possibility to obtain uniformity and mixing in atomic scale, the distribution of narrow particles, minor contamination of the product during the homogenization of the source connections, low energy consumption, low aging time and simple equipment ${ }^{4}$.

Research described in ${ }^{5}$, showed that the crystalline structure is a sequential process; the crystalline product is obtained at temperature of

This is an 2 Open Access article licensed under a Creative Commons Attribution-Non Commercial-Share Alike 4.0 International License (https://creativecommons.org/licenses/by-nc-sa/4.0/), which permits unrestricted Non Commercial use, distribution and reproduction in any medium, provided the original work is properly cited. 
$1100{ }^{\circ} \mathrm{C}$. Such particles are large in size and form large agglomerates. Therefore, it is worthwhile to seek alternative methods to synthesize weakly agglomerated nanoparticles $\mathrm{Bi}_{0,1} \mathrm{Dy}_{0,9} \mathrm{MnO}_{3}$ using organic compounds. It is possible to single out such methods as the citrate-nitrate synthesis and sol-gel. In these cases, the formation of nanoparticles will happen either during the decomposition of previously formed organic-inorganic complexes (precipitation and sol-gel method), or the isolated volume (trace elements); the parameters of which can be controlled by selection of various organic compounds. Therefore, the aim of this study was the synthesis of nanoparticles of manganite dysprosiumbismuth (BDMO) using different methods and the composition correction by radiography of the obtained nanoparticles.

\section{EXPERIMENTAL}

Three different methods of obtaining manganite BDMO were used in the work.

\section{Solid-state reaction}

In solid-phase reactions the source materials and the final products are in solid state, therefor the oxides may be mixed with the stoichiometric ratios. The manganite was synthesized by solid state reaction in the manner of mixing oxides of metal ions $\mathrm{Bi}^{3+}$, $\mathrm{Dy}^{3+}$ and $\mathrm{Mn}^{3+}$ corresponding to the formula of the perovskite $\mathrm{Bi}_{0,1} \mathrm{Dy}_{0,9} \mathrm{MnO}_{3}(\mathrm{BDMO})$, in the required proportion to obtain the final product with the desired composition.

Solid-phase synthesis of complex oxides based on manganite was made of a mixture of initial oxides in accordance with the following scheme of reactions.

$0,1 \mathrm{Bi}_{2} \mathrm{O}_{3}+0,9 \mathrm{Dy}_{2} \mathrm{O}_{3}+\mathrm{Mn}_{2} \mathrm{O}_{3}=2 \mathrm{Bi}_{0,1} \mathrm{Dy}_{0,9} \mathrm{MnO}_{3}$

Stoichiometric amounts of oxides were mixed and triturated in an agate mortar to obtain a homogeneous mixture. Then the mixtures were subjected to repeat annealing in a furnace in the temperature range of $600-1100{ }^{\circ} \mathrm{C}$ with increase temperature in every $100^{\circ} \mathrm{C}$. Annealing was made in 6 stages: I stage $-600{ }^{\circ} \mathrm{C}$, II - stage $-700{ }^{\circ} \mathrm{C}$, III - stage $800^{\circ} \mathrm{C}$, IV - stage $900{ }^{\circ} \mathrm{C}, \mathrm{V}$ - stage $1000^{\circ} \mathrm{C}, \mathrm{VI}$ - stage $1100^{\circ} \mathrm{C}$ with a total duration of
39 hours $^{5}$. Intermediate grinding was made after each synthesis stage. Upon completion of the synthesis, the furnace was turned off, and cooling of the obtained compound was in the cooling mode of the muffle furnace. The composition of the final products was controlled by the method of X-ray.

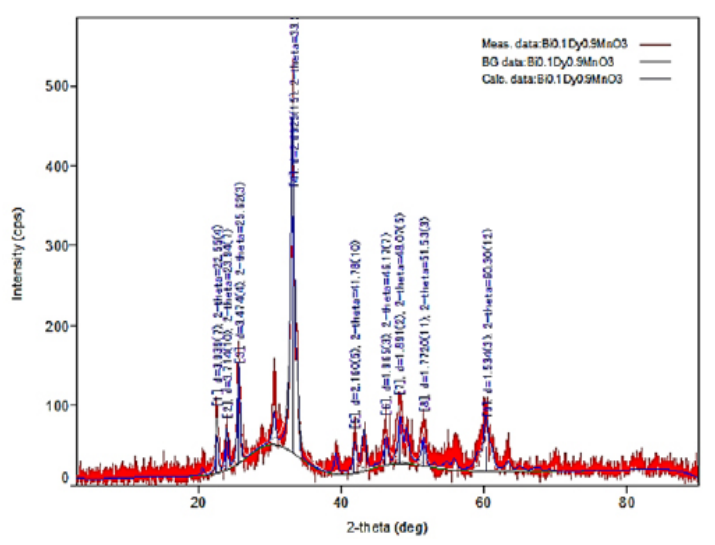

Fig. 1. The diffraction pattern of the composite synthesized by solid-phase method

By the results of the manganite diffraction pattern (Fig. 1), it can be seen that the resulting manganite is multiphase. In addition, it is necessary to note several shortcomings of this method.
a. Duration of synthesis (39 hours).
b. High synthesis temperature above $1000^{\circ} \mathrm{C}$.
c. Multiphase product.

\section{The sol-gel method using a polyatomic alcohol glycerol}

In this method of synthesis metal oxides were used too. The required amount of oxides was dissolved in distilled water. Citric acid and glycerol (2:3) were added to the obtained solution as gelling agents. Then the solution was heated using an electric stove with constant stirring at $80{ }^{\circ} \mathrm{C}$ to remove excess water and obtain viscous gels. The gel was dried at $250^{\circ} \mathrm{C}$ and annealed at $500{ }^{\circ} \mathrm{C}$ for $10 \mathrm{~h}$, to obtain the desired powder. The powders were crushed in an agate mortar to obtain a homogenous mixture. Then they were placed in crucibles and annealed at temperatures of $600-1000^{\circ} \mathrm{C}$ for 19 hours.

In Fig. 2 the peaks marked in blue indicate peaks before improvement phase and the peaks marked with pink are the remaining after the refinement of the phase by the Rietveld method. 


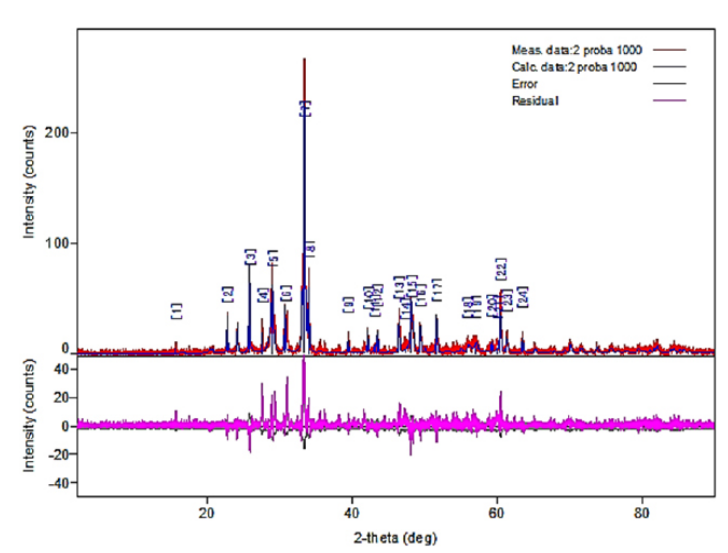

Fig. 2. The diffraction pattern of the manganite synthesized by the sol-gel method

\section{Citrate-nitrate method}

Perovskite type of BDMO was received by the citrate-nitrate method using as source oxides $\mathrm{Dy}_{2} \mathrm{O}_{3}$ (b.p.), $\mathrm{Bi}_{2} \mathrm{O}_{3}$ (b.p.), $\mathrm{Mn}_{2} \mathrm{O}_{3}$ (b.p.). Same as in the second method, the mixture of oxides was dissolved in distilled water. $2 \mathrm{M}$ nitric acid as a precipitating agent was added to the obtained solution. Citric acid in the ratio of the oxides 1:2 was used as the reaction medium. Chelating effect is favorable for $\mathrm{pH}$ value. Thus an adequate volume of $2 \mathrm{M}$ of solution $\mathrm{HNO}_{3}$ were added to increase the $\mathrm{pH}$ value of the mixtures up to 7 . The obtained mixture was evaporated using an electrical plate at $80^{\circ} \mathrm{C}$ and continuous stirring to remove the excess solvent before formation of the dry semi-product and annealed at $500{ }^{\circ} \mathrm{C}$ for $10 \mathrm{~h}$ to obtain the desired powder.

The presence of the source oxide in the mixture is maintained at a temperature of $700-800{ }^{\circ} \mathrm{C}$. At this with increasing temperature the manganese is rapidly recovered, being in a sample composition in the form of a mixture of oxides with different degree of oxidation. The bismuth oxide is finally included in the structure of solid solution based on dysprosium manganite at $800-900{ }^{\circ} \mathrm{C}$, the dysprosium oxide remains in the form of oxide or hydroxide up to $900{ }^{\circ} \mathrm{C}$, and then reacts. Final heat treatment of the precursors was performed in a muffle furnace at different temperatures $\left(900,1000^{\circ} \mathrm{C}\right)$ for $21 \mathrm{~h}$, in a muffle furnace. Formation of the new phase is completed at a temperature of $1000^{\circ} \mathrm{C}$.

In Fig. 3, the peaks marked in blue indicate peaks before improvement of the phase and the peaks marked with pink are the remaining after the refinement of the phase by the Rietveld method.

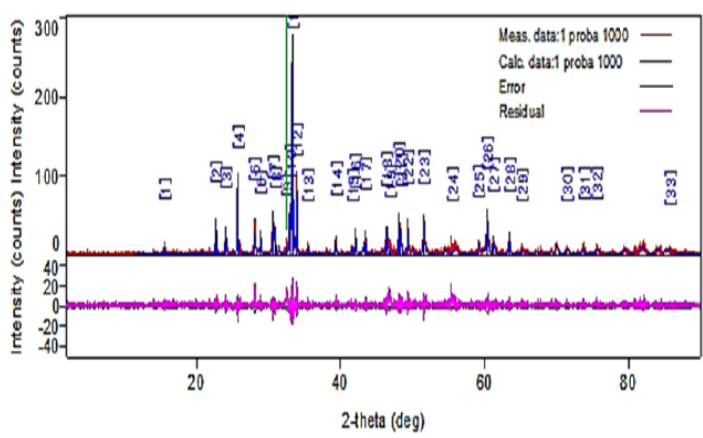

Fig. 3. The diffraction pattern of the manganite synthesized by citrate-nitrate method

\section{RESULTS AND DISCUSSION}

The formation of new phases was controlled by the method of $x$-ray phase analysis produced by X-ray diffractometer Miniflex 600 (Rigaku) using CuK $\alpha$-radiation filtered by the Ni filter $(U=30 \kappa V$, $\mathrm{J}=10 \mathrm{MA}$, the rotation speed of 1000 pulses per second, time constant $=5 \mathrm{sec}$., the range of angles $2 \theta$ from 5 to 900). Radiographs of the synthesized polycrystalline powders were indicated by the homology method (homologue is a distorted structure type of perovskite). The density of manganites were determined by the pycnometric method according to GOST 2211-65. Toluene served as indifferent liquid. The density of the manganite was measured $4-5$ times and data were averaged.

The results of the synthesized manganite radiograph indexing by different methods show that the manganites have the orthorhombic structure with the following unit cell parameters (Table 2).

The reliability of the indexing results is controlled by a satisfactory coincidence of experimental and calculated values of the inverse squares of the interplanar spacing's (104/d2), and the coincidence degree of the x-ray and pycnometric densities values of the studied compounds.

Thus, the double bismuth- manganite BDMO was synthesized by various methods. Using the ceramic technology, considering the Tamman's conditions, the authors defined temperature regime of the synthesis of the dual mixed manganite BDMO. The type of crystal system and unit cell parameters 
were determined by the radiographic method. It is established that a complex mixed manganite is crystallized in the orthorhombic crystal system; the correctness of the results of x-ray studies of the manganite is confirmed by the good concordance between the experimental and calculated values (104/d2), concordance between the values of $x$-ray and pycnometer densities. The comparative analysis of parameters between the lattice parameters of the source $\delta-\mathrm{Bi}_{2} \mathrm{O}_{3}$ shows that the values of the parameters «a» and «b» satisfactorily coincide with the lattice parameters $\delta-\mathrm{Bi}_{2} \mathrm{O}_{3}$, the parameter " $\mathrm{C}$ » is distorted from the value of the «a» parameter on $\sqrt{2}$.

Table 1: The results on indexing of radiographs of manganites synthesized with different methods

\begin{tabular}{|c|c|c|c|c|c|c|}
\hline No & [ $\left.{ }^{\circ} 2 \mathrm{Th}.\right]$ & $\mathrm{d}[\AA \AA \mathrm{A}]$ & Int. [\%] & $10^{4} / d^{2} \exp$ & hkl & $10^{4} / d^{2}$ theor \\
\hline \multicolumn{7}{|c|}{ Solid-phase method } \\
\hline 1 & $22.55(4)$ & 4.31421 & 2 & 537.27 & $(1,0,1)$ & 538.31 \\
\hline 2 & $23.94(7)$ & 3.91843 & 10 & 651.29 & $(1,1,0)$ & 653.52 \\
\hline 3 & $25.62(3)$ & 3.73505 & 12 & 716.81 & $(0,0,2)$ & 718.83 \\
\hline 4 & $33.247(19)$ & 3.47001 & 30 & 830.49 & $(1,1,1)$ & 833.52 \\
\hline 5 & $41.78(10)$ & 2.91993 & 10 & 1172.88 & $(0,2,0)$ & 1173.89 \\
\hline 6 & $46.17(7)$ & 2.71955 & 30 & 1352.09 & $(0,2,1)$ & 1354.15 \\
\hline 7 & $48.07(5)$ & 2.70358 & 100 & 1368.11 & $(1,1,2)$ & 1370.16 \\
\hline 8 & $51.53(3)$ & 2.64232 & 30 & 1432.28 & $(2,0,0)$ & 1435.3 \\
\hline 9 & $60.30(12)$ & 2.55575 & 0 & 1530.95 & $(1,2,0)$ & 1532.01 \\
\hline \multicolumn{7}{|c|}{ Sol-gel method } \\
\hline 1 & 11.38 & 7.769 & 0.2 & 165.67 & $(1,1,0)$ & 165.67 \\
\hline 2 & 16.12 & 5.494 & 1.8 & 331.3 & $(2,0,0)$ & 331.3 \\
\hline 3 & 19.78 & 4.486 & 6.5 & 496.91 & $(2,1,1)$ & 496.91 \\
\hline 4 & 22.87 & 3.885 & 2.7 & 662.54 & $(2,2,0)$ & 662.54 \\
\hline 5 & 25.62 & 3.474 & 2.2 & 828,59 & $(0,1,3)$ & 828,59 \\
\hline 6 & 28.11 & 3.172 & 100 & 993,88 & $(2,2,2)$ & 993,88 \\
\hline 7 & 30.42 & 2.936 & 3 & 1160,08 & $(1,2,3)$ & 1160,08 \\
\hline 8 & 32.57 & 2.747 & 37 & 1325,2 & $(4,0,0)$ & 1325,2 \\
\hline 9 & 34.61 & 2.59 & 3.9 & 1490,74 & $(4,1,1)$ & 1490,74 \\
\hline 10 & 36.54 & 2.457 & 1.7 & 1656,49 & $(0,2,4)$ & 1656,49 \\
\hline 11 & 38.4 & 2.342 & 2.3 & 1823,16 & $(3,3,2)$ & 1823,16 \\
\hline 12 & 40.18 & 2.243 & 0.6 & 1987,65 & $(4,2,2)$ & 1987,65 \\
\hline \multicolumn{7}{|c|}{ Citrate-nitrate method } \\
\hline 1 & 15.57 & 5.688 & 32.9 & 309,09 & $(0,0,1)$ & 309,09 \\
\hline 2 & 15.95 & 5.55 & 0.6 & 324,65 & $(1,1,0)$ & 324,65 \\
\hline 3 & 20.75 & 4.278 & 1.5 & 546,41 & $(0,2,0)$ & 546,41 \\
\hline 4 & 22.36 & 3.972 & 1.5 & 633,84 & $(1,1,1)$ & 633,84 \\
\hline 5 & 24.1 & 3.69 & 9.7 & 734,42 & $(1,2,0)$ & 734,42 \\
\hline 6 & 24.39 & 3.647 & 10 & 751,85 & $(2,0,0)$ & 751,85 \\
\hline 7 & 26.04 & 3.419 & 12.7 & 855,46 & $(0,2,1)$ & 855,46 \\
\hline 8 & 26.55 & 3.355 & 9.9 & 888,41 & $(2,1,0)$ & 888,41 \\
\hline 9 & 28.82 & 3.095 & 68 & 1043,95 & $(1,2,1)$ & 1043,95 \\
\hline 10 & 29.06 & 3.07 & 8.5 & 1061,02 & $(2,0,1)$ & 1061,02 \\
\hline 11 & 30.92 & 2.89 & 100 & 1197,3 & $(2,1,1)$ & 1197,3 \\
\hline 12 & 31.43 & 2.844 & 14.5 & 1236,35 & $(0,0,2)$ & 1236,35 \\
\hline 13 & 32.23 & 2.775 & 6.8 & 1317,52 & $(2,2,0)$ & 1317,52 \\
\hline 14 & 33.72 & 2.656 & 41.2 & 1417,57 & $(1,3,0)$ & 1417,57 \\
\hline 15 & 35.44 & 2.531 & 27.2 & 1561,05 & $(1,1,2)$ & 1561,05 \\
\hline
\end{tabular}


Table 2: The unit cell parameters of the manganite obtained by different methods

\begin{tabular}{lccccccccc}
\hline No & Obtaining method & a & $b$ & $c$ & Vun.cell., $\AA^{3}$ & $Z$ & $\begin{array}{c}P_{\text {X-ray }} \\
\mathrm{g} / \mathrm{cm}^{3}\end{array}$ & $\begin{array}{c}P_{\text {pyc }} \\
g / \mathrm{cm}^{3}\end{array}$ \\
\hline 1 & Solid-state reaction & 5.294 & 5.839 & 7.410 & 229 & 4 & 7.648 & 7.651 \\
2 & Sol-gel method & 5.2793 & 5.83 & 7.382 & 227.26 & 4 & 7.765 & 7.761 \\
3 & Citrate-nitrate method & 5.832 & 5.278 & 7.386 & 227.38 & 4 & 7.758 & 7.76 \\
\hline
\end{tabular}

\section{CONCLUSION}

BDMO manganite nanoparticles were synthesized in three ways. When using a solid-phase method multiphase manganite has been received. The use of sol-gel and citrate-nitrate methods made it possible to obtain single-phase crystalline nanoparticles in comparison with the solid-phase method. The solid-phase synthesis method is not optimal for obtaining dysprosium-bismuth manganite.

\section{ACKNOWLEDGMENT}

This article was prepared with the financial support of the grant of the Ministry of Education and Science of the Republic of Kazakhstan No 05130165 "Development and physical basis of new crystal systems in the class of multiferroics".

\section{REFERENCES}

1. Yener, D. O.; Giesche, H. J. Am. Cer. Soc., 2001, 84(9), 1987-1995.

2. Natarajan, U.; Handique, K.; Mehra, A.; Bellare, J. R.; Khilar, K.C. Langmuir., 2003, 2, $2670-2678$.

3. Uskokovic, V.; Drofenik, M. Mat. Sci. Forum., 2004, 453(4), $225-230$.
4. Uskokovic, V.; Drofenik, M. J.Magn.Magn. Mat., 2006, 303, $214-220$.

5. Mataev, M. M.; Saxena, S. M.; Tursinova, Zh. I.; Nurbekova, M. A.; Sarsenbaeva, Z. B.; Seitbek, A. Zh. Chem. J. Kazakhstan., 2017, 4, 181-188. 